\title{
EVA, PANDORA E CURUMIM: A \\ CURIOSIDADE E AS HISTÓRIAS
}

\author{
Cristina Keiko Inafuku \\ Daniela Waldman Teperman
}

${ }^{60}(2)$

uando Luicia Seláez era pequena, leu um romance escondida. Leu aos pedaços, noite após noite, ocultando o livro debaixo do travesseiro.

Lucia tinha roubado o livro da biblioteca de cedro onde seu tio guardava os livros preferidos.

Muito caminhou Lúcia, enquanto passavam-se os anos. Na busca de fantasmas caminhou pelos rochedos sobre o rio Antióquia, e na busca de gente caminhou pelas ruas das cidades violentas.

Muito caminhou Lúcia, e ao longo de seu caminhar ia sempre acompanhada pelos ecos daquelas vozes distantes que ela tinha escutado, com seus olhos, na infância.

Lúcia não tornou a ler aquele livro. Não o reconheceria mais. (1) livro cresceu tanto dentro dela que agora é outro, agora é dela.

At Eunção do Leitor - Eduardo Galeano

- Psicólogas, coordenadoras do ateliê de contar histórias do Lugar de Vida. 
A proposta do ateliê Contar Histórias da Pré-Escola Terapêutica Lugar de Vida ocorre no intervalo entre o sujeito e a cultura, entre o singular e o universal, entre a fantasia e a realidade. Isso porque a história ocorre neste intervalo. Ocorre em um mundo distante, no tempo do "Era uma vez", mas fala de questões cruciais, primeiras da humanidade. É por esse motivo, justamente, que as histórias sobrevivem através dos anos, séculos, milênios, dinastias, carregando em si verdades, significações que transpõem o tempo e o espaço e se atualizam com a escrita, através da verdade de cada ouvinte.

O objetivo do Contar Histórias é promover o contato e a escuta de histórias disponíveis na cultura. Trata-se de oferecer a essas crianças uma via de acesso ao registro do Simbólico. Para tanto, há um longo trabalho inicial, preparatório, que na prática ocorre possibilitando às crianças olhar histórias, folhear histórias, manusear histórias, cheirar histórias...

Alguns dispositivos presentes na instituição se atualizam neste espaço de histórias. Um deles é a alternância. A alternância, instrumento fundamental da montagem do Lugar de Vida, cuja função é promover a falta através da passagem de uma atividade para outra, ocorre também dentro da atividade do ateliê. Oferecemos um enquadre às crianças onde começo, meio e fim da atividade são bastante marcados. A história também encerra em si uma estrutura com começo, meio e fim ${ }^{2}$. Estrutura que é própria à narrativa com suas leis 
internas e que, por conseguinte, é da ordem da linguagem, do simbólico. É fundamental que a estrutura da história seja respeitada e cada momento contemplado para que a criança não fique suspensa no clímax, e para que algo da ordem do sentido possa emergir, já que é o fim que ressignifica o começo e que marca que aquela história - a contada - terminou.

Iniciamos o ateliê registrando os presentes e nomeando os ausentes, contamos uma história e ao final registramos algo do que aconteceu ali, algo que cada criança possa desejar querer deixar marcado. Através destas marcas, produzimos ali uma história, história de cada criança neste espaço de histórias. E esta produção - que recebeu o nome de "livrão" 3 - tem tido efeitos impressionantes em nós, nas crianças, na equipe como um todo. O "livrão" permite que um fio seja tecido de um encontro para outro, garante a retomada do trabalho, articulando memória e significação. Afinal, justamente o que grita nestes casos é a falta de uma história, de um fio, de um percurso... E contar histórias, narrar, tecer, fiar, não por acaso são palavras e ações que andam juntas. Há toda uma história que justifica estas associações.

Araújo (1992) refere-se à tradição, no nordeste, de contar histórias paralelamente à realização de trabalhos manuais, artesanais. Benjamin (1987) entende a narrativa como uma forma artesanal de comunicação, incluindo uma coordenação da alma, do olhar e da mão. Enquanto contamos histórias 
no ateliê, observamos que algumas crianças movimentam as mãos. Paula, por exemplo, nos pede uma panelinha e uma colherinha e fica ali, mexendo enquanto escuta.

Se por um lado, longitudinalmente, trabalhamos com a história contada paralelamente à construção da história das crianças no ateliê, por outro, na vertical, há dois eixos que norteiam a indicação do trabalho com histórias com crianças como aquelas que procuram o Lugar de Vida ${ }^{4}$. São eles: a inserção na cultura e a elaboração de fantasmas universais.

\section{A INSERÇÃO NA CULTURA}

A história oferece elementos da cultura, encerrando um movimento do universal para o singular. $O$ que Machado traduz nas seguintes palavras:

"Tal experiência diz respeito à universalidade do ser humano e, ao mesmo tempo, à minha existência como parte desta universalidade"

Paralelamente, a história possibilita o resgate de elementos latentes nas crianças, encerrando um movimento do singular para o universal. Este recurso oferece à criança a oportunidade de compartilhar com o grupo algo de sua origem, de sua filiação. Assim, quando contamos a história de um camponês que semeava a terra, Luíza diz: "Ele plantou jerimum?" Em momentos como este as crianças podem falar de coisas que conhecem e que falam delas.

\section{A ELABORAÇÃO DOS FANTASMAS UNIVERSAIS}

As produções como a história e o conto são portadoras de fantasmas universais, quais sejam: fantasma de retorno ao seio materno, de desmame, de nascimento, da cena primária, do romance familiar, da sedução e da castração (Araújo, 1992). Mais do que isso, tais produções são o resultado de elaborações psíquicas dos fantasmas inconscientes. São um canal de manifestação dos fantasmas inconscientes.

Afirmar que as referidas produções são portadoras dos fantasmas universais é dizer que tratam dos temas mais angustiantes da 
humanidade, como a origem da vida, a morte, o abandono, a perda dos pais, a sexualidade, etc.

Mannoni (1995) nos fornece exemplos de escritores famosos (como Edgar Allan Poe, Alfred Hitchcock e Ingmar Bergman) cujas produções exercem justamente a função acima relatada. $O$ desamparo e o horror vividos por esses autores, na sua infância, constituem a matéria-prima para suas produções.

A autora acredita que, para esses autores, a atividade criadora tem uma função libertadora. Através da produção literária, há reelaboração dos fantasmas, daquelas situações vivenciadas que não puderam ser faladas, elaboradas. Caso contrário, a repetição dessas cenas ocorreria no real, aprisionando este sujeito em um cotidiano insuportável, enlouquecedor.

"Assim, a violência inicial de uma vivência, tomada num trabalho posterior de simbolização e luto, consegue colocar-se em palavras, efetivando o desempenho cultural..."

Os autores citados por Mannoni têm em comum a necessidade de transpor aquilo que os atormenta. Para tanto, faz-se imprescindível um público/leitor - tais criações são concebidas para que outros participem delas - que se identifique com o horror das cenas vividas pelo autor. Procurando investigar por que essas histórias são lidas e por que há prazer em lê-las, dirá Mannoni:

"Os autores traumatizantes são fascinantes"

Esta frase foi selecionada com o objetivo preciso de frisar a importância de não se esvaziarem as histórias de seu conteúdo fantasmático - o que se faz, muitas vezes, buscando poupar a criança. Mas, nas palavras de Rodari (1982): causa..."

"O Lobo é (...) o sintoma que revela o medo, não a sua

O que Meneses (1987) frisa ao apontar quão positivo foi o fato de Sheherazade, em "As 1001 Noites", não ter expurgado de suas narrativas ao sultão histórias de adultérios e traições femininas. Aquelas eram justamente as questões que o atormentavam profundamente, que o levavam a casar-se a cada dia com uma virgem e a matá-la na manhã seguinte.

No ateliê Contar Histórias trabalhamos com histórias de origem chinesa, japonesa, norueguesa e russa, da tradição Sufi, contos de fadas, fábulas italianas, etc. Apoiando-nos na teoria, e também no êxito de Sheherazade, não excluímos das histórias seu conteúdo fanstasmático. Este aparece contextualizado na experiência de cada personagem e "toca" as crianças a partir de sua própria fantasmática. 


\section{O ESPAÇO DE HISTÓRIAS}

Como a proposta do ateliê Contar Histórias é promover a escuta de histórias, seria importante diferenciar 'escutar' de 'ouvir'. 'Ouvir' diz respeito a sons, ruídos, barulhos, e não necessariamente inclui a palavra. Já 'escutar' inclui algo da ordem do sentido. 'Escutar' diz respeito a um refinamento no ouvir, supõe comunicação com o outro. Assim, valoriza-se aqui a 'escuta' da história no sentido de um refinamento neste 'escutar' a cultura através de um outro. Outro que é a história e que é também o contador. Esta escuta pode vir a ser transformadora e pode propiciar as condições para o surgimento do espaço transicional.

Winnicott (1975), insatisfeito com a polarização mundo interno-mundo externo, propôs uma terceira instância: o espaço transicional, localizando-o no intervalo entre a criança e a mãe, entre o mundo externo e o interno, entre realidade e fantasia. $O$ autor afirma que as experiências da brincadeira e dos fenômenos transicionais formam os pilares onde se apoiará a experiência cultural. A cultura é pensada como tradição herdada, como um fundo comum à humanidade. A vivência com confiança da transicionalidade é fundamental para a experiência criativa e cultural posteriores da criança.

A escuta a que nos referimos é 
acompanhada de um esquecer-se de si mesmo, de um esvaziar-se, de uma concentração que gradativamente se constitui em distensão, em uma escuta flutuante. É apenas quando o ouvinte se esquece de si mesmo enquanto ouve a história, que aquilo que é ouvido se grava nele, tornando a experiência do ouvinte fundamental (Benjamin, 1987). Esta distensão, portanto, é condição para a experiência da transicionalidade.

A relação contador-ouvinte tem uma função criadora. Faz sentido um paralelo com a experiência daquele que ouve música, analisada por Silva (1993):

"O ato de ouvir é também transformador segundo seus próprios cânones prevalentes naquele momento, de modo que a mesma música não soa uniformemente a todos os seus ouvintes, antes sendo recriada também por estes."

Ou seja, cada ouvinte escuta a história a partir de sua singularidade, não há dois ouvintes iguais. Avançando um pouco mais, podemos dizer que nossos ouvintes - as crianças do Lugar de Vida escutam a história a partir dos recursos de que dispõem no momento, podendo sempre aproximar-se ou distanciar-se quando algo ali se torna insuportável.

Uma outra variável que atua neste espaço de histórias diz respeito ao narrador, ao contador de histórias. $O$ exemplo de Silva, neste caso, é também ilustrativo, permitindo-nos um paralelo entre o intérprete e o narrador:

"Como na música, o intérprete transforma o sentido possível, imprimindo-lhe seu estilo peculiar, comunicando ao ouvinte não só a partitura que executa, mas também sobre sua própria forma de sentir."

Este trecho exprime com exatidão a experiência do narrador, eliminando toda e qualquer possibilidade de se assumir uma suposta neutralidade daquele que conta histórias. Não é ingênuo o provérbio: "Quem conta um conto aumenta um ponto". Faz emergir a condição do contador: ele também é um sujeito, deseja, tem uma história, tem sua subjetividade e, quando conta histórias, conta também de si.

Desta forma, o espaço de histórias é uma conjugação de estruturas inconscientes, uma trama de subjetividades, onde contador e ouvinte criam e recriam a história ininterruptamente, colorindo-a com seu mundo interno.

“Narrador e ouvinte estarão assim intimamente ligados pela experiência, na qual, um deles mergulha em si para revelar uma história a si e ao outro, e este último abstrai-se de si mesmo para se deixar penetrar pelo outro através da história. Nestes termos a narrativa produz intimidade". (Araújo, 1992). 


\section{A ESCOLHA DAS HISTÓRIAS E AS HISTÓRIAS ESCOLHIDAS}

No decorrer do trabalho, vêm ocorrendo mudanças na escolha e oferta de histórias. A escolha, muitas vezes, é realizada previamente, em função de um tema ou até mesmo de um pedido. Noutras, a escolha ocorre ali, naquele primeiro momento, quando marcamos os nomes das crianças presentes e também das ausentes. É importante ressaltar esta passagem, recente no cotidiano do ateliê, da escolha das histórias por nós - coordenadoras e sustentadoras desta atividade - para as histórias que vêm sendo escolhidas pelas crianças. Estas últimas vêm sendo viabilizadas por uma pequena biblioteca que fica à disposição das crianças para a investigação, a curiosidade, a escolha e o manuseio. $\mathrm{Na}$ biblioteca encontram-se disponíveis diversos livros e também gibis e revistas. A inclusão destes dois artigos ocorreu em função do interesse específico de algumas crianças. A idéia é construir a possibilidade junto às crianças de que esta pequena biblioteca assuma as características que lhe são intrínsecas, ou seja, fazer circular as histórias da cultura. Avaliamos que poderá ser muito interessante que as crianças possam levar para casa uma destas histórias escolhidas para que seus pais possam contá-las...

Contemos então algumas histórias. Pedrinho tem especial interesse pelas histórias e temas de origem oriental. Ficou fascinado pela história "Issum Boshi", cantarolando durante a narrativa um cântico oriental. Após o final da história, dirigiu-se a outra criança do grupo - não por coincidência de origem chinesa - dizendo: "Agora eu vou contar esta história para você, Maria!"

Nas semanas seguintes, Pedrinho pede insistentemente a mesma história. Certo dia, encontra e seleciona numa revista a foto de um sushiman vestido com roupas típicas. Uma história, uma canção, uma figura passam a ganhar destaque a partir de uma escolha e articulação muito particulares.

As crianças também extraem das narrativas palavras com um poder diferenciado, palavras escutadas, proferidas e preferidas de forma singular. Estas apontam para algo de sua subjetividade, de seu fantasma, e podem ser colocadas em circulação em um discurso compartilhado.

Luíza escuta atentamente a história "O Sonho de Ícaro" e ao final se propõe a recontá-la: "Era uma vez um Ícaro chamado Roberto, ele foi ao shopping tomar sorvete". Na semana seguinte, começa a recontar a história de Pinóquio: "Era uma vez um Pinóquio chamado Roberto e saiu para tomar sorvete". Ícaro, Pinóquio, Roberto, nomes... Nomes que dificilmente desempe- 
nham para estas crianças seu papel de significante, representando e sustentando-as no discurso. Mas, na oferta de tantos nomes, quem sabe um em especial não possa ser privilegiado adquirindo seu valor significante? Para tanto, é fundamental que renunciemos a impor um nome correto a personagens e histórias, distanciandonos marcadamente de uma abordagem pedagógica no trabalho com histórias. Aqui, faz sentido falar em escuta psicanalítica.

As histórias propiciam um contexto onde as falas das crianças podem ser inseridas na narrativa sob a forma de jogo, de brincadeira. Antonio folheia o livro: "O monstro do lago" dizendo: "É o mar... tem peixinho." Depois pergunta: "Tem sereia?" $E$ acrescenta: "Tem jacaré, o jacaré vai comer..." O lago passa a ser o mar, o monstro passa a ser o peixinho, a sereia ou o jacaré; a história passa a ser a História de Antonio.

Alex identifica o ateliê com "Branca de Neve" e assim se dirige a nós quando nos vê. Sua atenção é voltada para a leitura do texto dos livros, mas se trata de uma leitura colada às palavras, sem atribuição de significação. Quando não está lendo, Alex parece desconectado do que ocorre à sua volta. Mas escutando um pouco mais estas palavras que "saem" de Alex observamos situações supreendentes. Certo dia, enquanto ocorria uma reunião de pais na sala ao lado - e as crianças estavam especialmente agitadas - Alex começa a ler um catálogo com as publicações de uma editora. Ele seleciona, dentre os inúmeros títulos, alguns para ler em voz alta: "Papai, mamãe e eu", "A mamãe e a menininha" e "Papai não é perfeito". Em sua relação peculiar com as palavras, Alex traduziu o não-dito que circulava no grupo, e falou também de sua história.

Até o presente momento, trouxemos, à guisa de exemplo, situações com crianças que dispõem da fala, evidenciando que o uso da narrativa oferece substrato para colocar em movimento algumas. Cabe agora contar como se dá a apropriação das histórias pelas crianças que não falam.

Assim que chega à sala, Márcia dirige-se diretamente ao armário e carrega o maior número possível de livros para o canto da sala onde constumamos reunir-nos. Há algum tempo temos observado que, dentre a variedade de livros que ela espalha a seu redor, alguns são olhados com mais atenção e retidão. Márcia folheia repetidamente o livro "Contos de Grimm" (livro que apresenta muito texto e algumas figuras) acompanhando cada página com sons, risos e gesticulações. Outro livro escolhido por Márcia "A viagem de Carlinhos" - se contrapõe ao anterior já que tem figuras grandes e chamativas. Há aí, neste movimento de Márcia, uma certa forma de apropriação da história, própria desta criança, já que suas gesticulações e movimentos não são estereotipados, mas "animam"de modo vivo as imagens que ela recolhe. 
Nelson, durante longo tempo apresentava interesse único e exclusivo por vasos sanitários. Não demonstrava qualquer interesse pelos livros ou histórias. Seus primeiros contatos com os livros eram afoitos, virava as páginas com uma rapidez que nos levava a desconfiar de que pudesse discriminar alguma figura ou forma. Esta hipótese, porém, não se comprovou, pois Nelson selecionou um dia uma pequena figura com uma privada e uma banheira, deixando o livro aberto diante de si. Nas semanas seguintes procurava aflito o mesmo livro, a mesma figura. Algum tempo depois, agora menos afoito, passou a selecionar outros livros, abrindo espaço para novos temas, como o quarto, a cama, a casa: novos lugares.

E por falar em lugar, não é este um significante que percorre todo o trabalho? Oferta de histórias, oferta de lugar, lugar de sujeito, sujeito que deseja, deseja um lugar ... um Lugar de Vida?

\section{A CURIOSIDADE E AS HISTÓRIAS}

"Haveria que se fazer um estudo antropológico da curiosidade, e do papel que ela desempenha em várias religiões e mitologias: desde a curiosidade de Eva, atiçada pela serpente, na narrativa mítica do paraíso, ... passando pela curiosidade de Pandora, que abre a fatídica caixa de males 
que se espalharão pela terra, ... até a curiosidade do curumim que abre o coco do Tucumã que encerra noite, fazendo com que a escuridão se espalhasse pelo mundo, como na lenda indígena brasileira."

Meneses discorre sobre a curiosidade na história da humanidade, definindo-a como necessidade imperiosa de conhecer. As histórias disponíveis na cultura (em sentido amplo) mobilizam de forma inquestionável a curiosidade nos seus ouvintes. $O$ suspense é um dos principais recursos utilizados para prender a atenção de crianças e adultos, despertando sua curiosidade. $O$ suspense alude a algo que está por vir, introduzindo neste momento a espera, a renúncia a uma satisfação imediata. O que acontecerá depois? Como poderá solucionarse tal conflito? E no final, a princesa casa-se com o mocinho? $O$ suspense deixa em suspenso uma resposta, protelando-a para sustentar uma demanda. Neste sentido, a curiosidade é qualidade daqueles que conseguem postergar a realização de um desejo para dar lugar à sua manutenção enquanto motor propulsor de novos conhecimentos. Necessariamente, para que haja desejo deve haver falta, e aqui entramos no jogo entre princípio do prazer e princípio de realidade, entre gozo e saber.

Kupfer (1996) relaciona conhecimento e sexualidade em "Educação Terapêutica", e afirma que quando uma criança pergunta, o que está em jogo é a curiosidade acerca das origens. A criança quer 
saber sobre a castração. O perguntar é característica própria à criança neurótica. É sua curiosidade sexual pela cena primária o que inspira toda a sua curiosidade por conhecer. Dirá Freud (1905) nos Três Ensaios Sobre a Sexualidade:

"Na mesma época em que a vida sexual da criança alcança seu primeiro florecimento, o que ocorre do terceiro ao quinto ano, aparecem nela os primeiros indícios desta atividade denominada pulsão de saber..."

Mas, retomando o texto de Kupfer, sobre a castração não se quer saber. Este saber é recalcado. Assim, após uma sofrida renúncia a este saber, o desejo de saber é exercido sobre outros objetos, ou seja, sobre o conhecimento acumulado através dos tempos. Agora, saber e gozo se excluem mutuamente. Quanto mais se sabe acerca de um objeto, mais distante se está do gozo. "Por isso não paramos de produzir saber".

Mas a criança psicótica é também curiosa? Se entendemos que a criança psicótica tem falhas na sua inscrição primordial, que estas obturam a curiosidade (assim como obturam a falta) então a criança não tem para onde dirigir a sua interrogação. Por isso é comum que uma mãe nos diga: "Meu filho fala direitinho, mas não faz perguntas". Nas palavras de Kupfer:

"As investigações sexuais podem ocorrer de forma pontual e parcial, mas não se dão sob a égide da castração. $O$ desejo, que se produz pelo efeito da falta, também não se constitui. O psicótico se põe em posição de objeto para o gozo do outro, por isso não quer saber sobre o objeto com o qual o outro goza. Assim, o psicótico não demanda amor. E não quer saber. Não pergunta..."

No ateliê Contar Histórias a idéia é promover curiosidades fragmentárias ${ }^{5}$, fabricar e administrar a curiosidade, enfatizando elementos que capturam a criança, sem perder de vista a estrutura da história. Satisfazer a curiosidade significa prazer, postergá-la significa cultura. Administrar a curiosidade é sair do gozo e entrar na cultura. Pois é intrínseco à cultura o adiamento da realização do prazer. Neste sentido, é ilustrativa a conduta de Maria.

Maria demonstrava especial interesse pela caixa de materiais (que continha objetos, panos, material gráfico, etc, e cujo uso estava regulado por uma lei: a caixa só podia ser aberta após a história). Assim, durante a história, ela - que não fala - acenava com as mãos em direção à caixa, por um momento a abria, dando uma furtiva olhadela e voltava a fechá-la. Depois, no momento em que a abertura da caixa já não era mais proibida, Maria não demonstrava o mesmo interesse. Aqui, parece estar em jogo algo da curiosidade e, por que não, do desejo. Mas também o jogo com o suspense, com a possibilidade de esperar...

O jogo estabelecido com a caixa por Maria envolve prazer, mas 
ao mesmo tempo, parece ser estruturante. Aqui, a regra, o interdito, operam sobre Maria. A partir da vontade, do desejo de abrir a caixa, ela joga com a regra, externa a ela mas que lhe diz respeito. Maria não se coloca como alheia à regra deste ateliê - do qual faz parte mas joga com a possibilidade, prazerosa, de burlá-la.

\section{O PERCURSO DE ANA NO CONTAR HISTÓRIAS}

Antes de encerrar, gostaríamos de contar a história de Ana no ateliê contar Histórias. Desde o início observamos que Ana ouve a história, e faz isso em silêncio. Muitas vezes escuta mexendo em panelinhas e fazendo comidinhas. Assim, ela nos conta sobre sua escuta, onde a tradição, aspectos culturais são atualizados, como a conjugação das mãos e do olhar descrito por Benjamin.

Ana se interessa pelas coisas de mulheres, pelos príncipes e princesas. Um dia, quando a contadora pergunta a Ana se ajuda sua mãe em casa, conta sobre coisas que faz como lasanha e macarrão. No mesmo dia, podemos observar um desencontro de Ana com a história, ela volta as costas para o grupo, e portanto para a história. O momento da história em que Ana se virou pôde ser registrado, foi quando a narradora contou que o pai da moça queria casá-la com o rei.

Nesse ponto a história tocou Ana, tocou em algo com que não sabe ou não pode lidar. Por isso, talvez, ela tenha precisado virar-se de costas. Há aqui um efeito. Formulamos algumas hipóteses. Talvez ela tivesse se identificado com a personagem, impelida a fazer algo que não quer, talvez o rumo da história fosse diferente do desejado. Não sabemos...

Noutro dia, mais adiante, Ana copia o nome do príncipe e escolhe o mesmo nome para registrar no livrão. Não foi uma simples palavra, mas uma palavra que chamou sua atenção, que a interessou especialmente. Ao escolhê-la, ela nos conta algo de si. Nem todas as crianças escolhem algo para registrar, muitas ficam angustiadas, outras deixam um enorme vazio. Ana pôde realizar uma escolha. Ainda que no campo da transicionalidade - que não é a realidade nem a fantasia - aparece aqui a possibilidade de desejar. No trânsito realidade externa - realidade interna, surge a possibilidade de oferecer à criança um lugar, lugar de sujeito, de quem escolhe algo, ainda que seja uma única palavra...

Enquanto escuta a história, Ana escolhe uma flor para ser 
encontrada pela personagem. Ela desenha a flor e chama a atenção da coordenadora para que olhe seu desenho. Desenha também uma casa. A escuta de Ana é ativa, ela traz elementos para a história e com esses elementos, na sua escolha, imprime marcas suas, que têm um sentido para ela.

Indagada sobre o que é uma flauta, Ana diz que uma flauta é de tocar, conduzindo-nos ao seu repertório cultural. Algo de seu imaginário é também despertado pela escuta quando Ana nos conta que um rio é algo "cheio de piscina". Na mesma história, quando aparece algo terrível - os ratos Ana vira o conteúdo da caixa (com panos, bonecos, brinquedos) no chão. Novamente a escuta produz efeitos em Ana.

Noutro dia Ana pergunta à coordenadora (que descrevia o choro de uma personagem): "Você chora também?" A história não apenas ressoa no íntimo de Ana, mas aquilo transborda, os fantasmas vem à tona. Ana consegue formular uma questão. Questão que lhe diz respeito, diz respeito à sua história.

Quando a contadora descreve uma princesa e pergunta como poderia ser seu nome, Ana diz que o nome da princesa era Príncipe, e depois Princesa Amada. O tema da sexualidade, das diferenças homem/mulher, vem à tona. Seguramente são temas que a mobilizam, e o contato com a história parece estar auxiliando-a a lidar/elaborar tais questões/conflitos. Como já foi dito, as histórias falam justamente dos medos do 
homem, de seus conflitos.

Escutando o percurso de Ana, podemos questionar-nos acerca dos efeitos da escuta de histórias sobre as crianças do Lugar de Vida. Nesse sentido as palavras de Machado são esclarecedoras:

"O que importa é que o conto estabelece uma conversa entre sua forma objetiva - a narrativa - e as ressonâncias subjetivas que desencadeia, produzindo um determinado EFEITO particular sobre cada ouvinte...acredito que o importante não é querer saber qual o efeito sobre cada criança, ou mesmo 'produzir um efeito', mas sim entender que para cada criança aquela história traz o oportunidade de organizar suas imagens internas em uma FORMA que faz sentido para ela naquele momento. É como se ela pudesse passear pelo reino das possibilidades de significar, inventando para si mesma a sua estória naquele momento"

Conceber o trabalho da mesma forma que Machado supõe uma renúncia, um descontrole. Ao terminar, não solicitamos à criança que desenhe, que fale, que comprove que escutou a história. Ao contrário, após a história há o tempo de brincar... Às vezes, brinca-se com a história, com seus personagens. E é este o limite do trabalho. Por hora, continuamos a contar, tecer, fiar, escutar histórias... 


\section{REFERENCIAS BIBLIOGRÁFICAS}

ARAÚJO, M.G.C. Histórias de amor no cordel e psicoterapia. São Paulo, 1992. Tese (Doutorado). Instituto de Psicologia - Universidade de São Paulo, 1992.

- BENJAMIN, W. O narrador - considerações sobre a obra de Nikolai Leskov. In: Magia e técnica, arte e política. São Paulo, Brasiliense, 1987

- FREUD, S. Três ensaios sobre a Sexualidade. In: Obras Completas. Editorial Biblioteca Nueva, Volume II, Madrid, 1905.

- KUPFER, M.C. Educação terapêutica. (Apostila)

- MACHADO, R. Agora eu era o herói e o meu cavalo só falava inglês. (Apostila).

- MANONNI, M. Amor, ódio e separação. Rio de Janeiro, Jorge Zahar, 1995.

- MENeSES, A. B. Do poder da palavra. Revista Remate de Males, n. 7, Campinas, 1987.

- RODARI, G. Gramática da fantasia. São Paulo, Summus, 1982.

- SILVA, M.E. Pensar em psicanálise. In: Investigação e psicanálise. Campinas, Papirus, 1993.

- TEPERMAN,D.W.- A História e o Conto como dispositivos terapêuticos. Trabalho de conclusão de curso apresentado na PUC-SP em 1995.

- WINNICOTT, D.W. O brincar \& a realidade. Rio de Janeiro, Imago, 1975.

\section{NOTAS}

1 GALEANO, E. O livro dos abraços. Porto Alegre, L\&PM, 1991.

2 No texto de apresentação do "Lugar de Vida", neste número, Kupfer afirma: "Em uma criança dita psicótica o que falta é a falta. ... A falta de um ponto final, de uma pausa no enunciado, de um momento de conclusão, impede a emergência de um sentido. ... Falta-lhes (às crianças) esse momento de interrupção, e o sentido não pode então advir" (ver a página no texto de apresentação)

3 Trata-se da confecção de um livro com os referidos registros e marcas produzidas por nós e pelas crianças durante cada semestre de atividades.

4 Crianças com hipótese diagnóstica de psicose, autismo ou neurose grave.

5 Teorização realizada por Alfredo Jerusalinsky em seminários proferidos na USP. 